\title{
Patients with acute coronary syndromes without persistent ST elevation undergoing percutaneous coronary intervention benefit most from early intervention with protection by a glycoprotein IIb/IIla receptor blocker
}

\author{
E. Ronner ${ }^{1}$, E. Boersma ${ }^{1}$, K. M. Akkerhuis ${ }^{1}$, R. A. Harrington ${ }^{2}$, A. M. Lincoff ${ }^{3}$, \\ J. W. Deckers' ${ }^{1}$, K. Karsch ${ }^{4}$, N. S. Kleiman ${ }^{5}$, A. Vahanian ${ }^{6}$, \\ E. J. Topol ${ }^{3}$, R. M. Califf ${ }^{2}$ and M. L. Simoons ${ }^{1}$ \\ ${ }^{1}$ University Hospital Rotterdam, Rotterdam, The Netherlands; ${ }^{2}$ Duke Clinical Research Institute, Durham, \\ North Carolina, U.S.A.; ${ }^{3}$ Cleveland Clinic Foundation, Cleveland, Ohio, U.S.A.; ${ }^{4}$ the Bristol Heart Institute, \\ Bristol, U.K.; ${ }^{5}$ Baylor College of Medicine and the Methodist Hospital, Houston, Texas, U.S.A.; ${ }^{6}$ Tenon Hospital, \\ Paris, France
}

\begin{abstract}
Background Many patients with acute coronary syndromes are offered percutaneous coronary intervention. However, the appropriate indications for, and optimal timing of, such procedures are uncertain. We analysed timing of intervention and associated events (death and myocardial infarction) in the PURSUIT trial in which 9461 patients received a platelet glycoprotein IIb/IIIa inhibitor, eptifibatide, or placebo for $72 \mathrm{~h}$. Other treatment was left to the investigators. 2430 patients underwent percutaneous coronary intervention within 30 days. Four groups were distinguished, who underwent percutaneous coronary intervention on day 1 ; on days 2 or 3 ; at 4 to 7 days; or between 8 until 30 days, for eptifibatide- and placebo-treated patients.
\end{abstract}

Results The four groups treated with placebo demonstrated total 30 -day events of $15.9 \%$ for day 1 percutaneous coronary intervention, $17 \cdot 7 \%, 15 \cdot 0 \%$ and $18 \cdot 2 \%$, respectively, for successive intervals of later intervention. Later intervention was associated with more pre-procedural events $(2 \cdot 2 \%$ to $13 \cdot 7 \%, P=0 \cdot 001)$ which was balanced by a decrease in procedure-related events $(12 \cdot 1$ to $3 \cdot 1 \%$, $P=0.001$ ), while the overall 30 -day event rates were similar. Eptifibatide-treated patients with percutaneous coronary intervention on day 1 had the lowest rate of 30-day events $(9 \cdot 2 \%, P<0 \cdot 05$ vs other groups). In this group, pre-procedural risk was only $0 \cdot 3 \%$, while percutaneous coronary intervention on eptifibatide treatment was associated with low procedural risk $(7 \cdot 2 \%)$. The total 30 -day event rate for later percutaneous coronary intervention in patients receiving eptifibatide was 14.0 on days 2 and $3,15 \cdot 0 \%$ for days 4 to 7 and $17 \cdot 4 \%$ for days 7 to 30 , respectively.

Conclusion Patients treated with a platelet glycoprotein IIb/IIIa receptor blocker, and early percutaneous coronary intervention (within $24 \mathrm{~h}$ ) had the lowest event rate in this post hoc analysis. Thus 'watchful waiting' may not be the optimal strategy. Rather an early invasive strategy with percutaneous coronary intervention under protection of a platelet glycoprotein IIb/IIIa receptor blocker should be considered in selected patients. Randomized trials are warranted to verify this issue.

(Eur Heart J, 2002; 23: 239-246, doi:10.1053/euhj.2001. 2736)

(C) 2001 The European Society of Cardiology

Key Words: Acute coronary syndromes, revascularization, unstable angina pectoris, platelet aggregation inhibitors, eptifibatide, myocardial infarction.

See page 194, doi: 10.1053/euhj.2001.2911 for the Editorial comment on this article

Revision submitted 9 April 2001, accepted 11 April 2001, and published online 14 August 2001.

PURSUIT was supported by COR Therapeutics, Inc., South San Francisco, California and the Schering-Plough Research Institute, Kenilworth, New Jersey, U.S.A.

Correspondence: Prof Maarten L. Simoons, University Hospital Rotterdam, Thoraxcenter Cardiology, room H560, Dr. Molewaterplein 40, 3015 GD Rotterdam, The Netherlands. 


\section{Introduction}

A wide range of treatment strategies have been developed for patients with acute coronary syndromes without persistent ST-segment elevation. These strategies can be categorized as early invasive or conservative $e^{[1-3]}$. Recent randomized investigations provided evidence of better outcome with an invasive strategy. Similar 30-day and 6-month complication rates were reported in some earlier trials ${ }^{[4,5]}$. In particular, the recent FRISC-II study reported favourable survival after an early invasive treatment strategy ${ }^{[6]}$. The TACTICS trial, incorporating platelet GPIIb/IIIa receptor blocker glycoprotein (GP) IIb/IIIa receptor blockers, demonstrated benefit from invasive treatment too ${ }^{[7]}$. However, selection of the most suitable therapy in individual patients remains a challenge, and the early application of percutaneous interventions or coronary surgery and the timing of such an intervention is largely dependent on local practice and facilities $^{[8,9]}$.

Several registries of percutaneous coronary interventions in acute coronary syndromes have reported an increased risk of thrombotic complications during the procedure ${ }^{[10,11]}$. This risk was highest in patients treated during the acute phase, and lowest in patients who were stabilized for a few days or weeks by medical therapy. Accordingly, a strategy of 'watchful waiting' has been recommended. The recent introduction of platelet glycoprotein IIb/IIIa blockers, however, may change this paradigm, as these agents prevent thrombotic complications during medical treatment as well as during percutaneous coronary intervention ${ }^{[12,13]}$. We attempted to gain insight into the relationship between the timing of percutaneous coronary intervention, the use of glycoprotein IIb/IIIa inhibitors and patient outcome, by analysing data from the large Platelet Glycoprotein IIb/IIIa in Unstable Angina: Receptor Suppression Using Integrilin Therapy (PURSUIT) trial of eptifibatide versus placebo in patients with non-ST-elevation acute coronary syndromes ${ }^{[14]}$.

\section{Methods}

\section{Patient population}

The design and methods of the PURSUIT trial have been described in detail elsewhere ${ }^{[13]}$. In summary, patients were eligible if they presented within $24 \mathrm{~h}$ of an episode of ischaemic chest pain $(>10 \mathrm{~min})$, and had either transient ST elevation $(>0.5 \mathrm{~mm})$, transient or persistent ST depression $(>0.5 \mathrm{mV})$, T-wave inversion $(>0.1 \mathrm{~mm})$, or elevation of the creatine kinase $\mathrm{MB}$ fraction above the upper limit of normal. Patients with persistent (>30 min) ST elevation were excluded. There were no age restrictions. Eligible patients were randomly assigned to treatment with eptifibatide or placebo for $72 \mathrm{~h}$. Additional treatment, including percutaneous coronary intervention or coronary artery bypass grafting $(\mathrm{CABG})$ was at the discretion of the treating physician.
If a percutaneous coronary intervention was performed during the first $72 \mathrm{~h}$, study medication could be continued for another $24 \mathrm{~h}$. The PURSUIT trial enrolled 9461 patients.

\section{Definition of myocardial infarction}

The primary efficacy end-point of PURSUIT was a composite of death or non-fatal myocardial infarction at 30 days. Within $18 \mathrm{~h}$ of enrolment myocardial infarction was diagnosed on the basis of ischaemic chest pain and new ST-segment elevation. After $18 \mathrm{~h}$, myocardial infarction was diagnosed on the basis of new Q waves, or new or repeated creatine kinase MB fraction elevations above the upper limit of normal. For patients undergoing a percutaneous intervention, a creatine kinase MB fraction elevation more than three times the upper limit of normal was required. End-points were adjudicated by a central Clinical Events Committee. A computerized algorithm was used to review the raw data. If a possible complication was identified, further documentation was collected and the case reviewed in detail. Local investigators also reported whether or not the patient had had an acute myocardial infarction. Discrepancies between the clinical events committee opinion and that of the investigator have been investigated and discussed in detail ${ }^{[15]}$. This analysis presents data based on the clinical events committee judgement. Differences with analyses that are based on the investigators' opinion are discussed, but the pertinent data will not be shown.

\section{Statistical analysis}

There were 2419 patients (26\%) undergoing a percutaneous coronary intervention within 30 days of enrolment, without a prior CABG in this period. These patients were divided into four groups of approximately the same size according to the timing of the intervention: within $24 \mathrm{~h}$ of randomization (day 1), within 24-72 h (days 2-3), within 73-168 h (days 4-7), and within 169-720 h (days 8-30), respectively. These intervals were divided at complete days to enable comparison with clinical practice, choosing groups of roughly equal size. Chi-squared tests, Student's t-tests and one-way analyses of variance were applied to investigate differences in baseline characteristics between these groups as well as between patients undergoing percutaneous coronary intervention and those not undergoing percutaneous coronary intervention. Results are compared between the four groups with and without eptifibatide. In addition the results are compared with patients treated conservatively.

Adverse cardiac complications (death or myocardial infarction) were separated as occurring during the period of initial medical management (i.e. among all patients before a percutaneous coronary intervention or CABG, if any), within $48 \mathrm{~h}$ after the start of a percutaneous coronary intervention procedure 
Table 1 Baseline characteristics

\begin{tabular}{|c|c|c|c|c|c|c|}
\hline $\begin{array}{l}\text { PCI* on day } \\
\text { Number of patients } \\
\text { Hours (days) to PCI, median }\end{array}$ & $\begin{array}{c}1 \\
620 \\
11 \\
(0 \cdot 5)\end{array}$ & $\begin{array}{c}2-3 \\
624 \\
46 \\
(1 \cdot 9)\end{array}$ & $\begin{array}{r}4-7 \\
614 \\
110 \\
(4 \cdot 6)\end{array}$ & $\begin{array}{c}8-30 \\
561 \\
305 \\
(12 \cdot 7)\end{array}$ & $\begin{array}{l}\text { All patients } \\
2419 \\
72 \\
(3 \cdot 0)\end{array}$ & $\begin{array}{c}\text { Other } \\
7042 \\
-\end{array}$ \\
\hline Mean age, years & 59 & 59 & 61 & $62 \S$ & 61 & $64 \S$ \\
\hline Male gender, $\%$ & 68 & 70 & 70 & 73 & 70 & $63 \S$ \\
\hline Hypertension, $\%$ & 59 & 54 & 54 & $48 \S$ & 53 & $56 \dagger$ \\
\hline Diabetes mellitus, $\%$ & 21 & 22 & 21 & 18 & 20 & $24 \S$ \\
\hline Current smoker, $\%$ & 34 & 32 & 33 & 33 & 33 & $27 \S$ \\
\hline Previous MI, \% & 31 & 26 & 31 & 26 & 28 & $34 \S$ \\
\hline CCS class III or IV in previous 6 weeks & 49 & 42 & 48 & 49 & 47 & $42 \S$ \\
\hline Previous heart failure & 6 & 6 & 7 & 6 & 6 & $13 \S$ \\
\hline Previous CVA & 2 & 4 & 2 & 4 & 3 & $4 \dagger$ \\
\hline Peripheral vessel disease, $\%$ & 6 & 4 & 7 & $8 \dagger$ & 6 & $9 \S$ \\
\hline Previous CABG & 15 & 15 & 13 & 12 & 14 & $11+$ \\
\hline Previous PCI & 25 & 21 & 19 & $13 \S$ & 20 & $10 \S$ \\
\hline Elevated cardiac enzymes at admission & 45 & 48 & 49 & 46 & 47 & 45 \\
\hline ST depression at admission & 38 & 39 & 45 & $49 \S$ & 43 & $53 \S$ \\
\hline Mean systolic blood pressure, $\mathrm{mmHg}$ & 127 & 130 & 130 & $131 t$ & 130 & $132 \S$ \\
\hline Mean heart rate, beats $\min ^{-1}$ & 71 & 72 & 72 & 71 & 71 & $74 \S$ \\
\hline Study medication eptifibatide & 49 & 49 & 47 & 48 & 48 & 50 \\
\hline
\end{tabular}

* Patients undergoing a PCI within 30 days of enrolment, without a prior CABG in this period; $\dagger P<0 \cdot 05 ; \ddagger P<0 \cdot 01 ; \S P<0 \cdot 001 ; \mathrm{CABG}=$ coronary artery bypass grafting; $\mathrm{CCS}=\mathrm{Canadian}$ Cardiovascular Society; $\mathrm{CVA}=$ cerebrovascular accident; $\mathrm{MI}=$ myocardial infarction; $\mathrm{PCI}=$ percutaneous coronary intervention.

(peri-procedural complications), or in the period $48 \mathrm{~h}$ after the percutaneous coronary intervention procedure and during 30 days of follow-up (post-procedural complications). The complications were separated to enable detailed insight into procedure-related events, which are likely to be influenced by the timing of the percutaneous coronary intervention. Total 30 -day event rate describes the percentage of patients with any event. As multiple events have occurred in certain patients, the sum of pre- peri- and post-procedure events can be higher than the total 30-day (patients-with-) event rate. Complication rates in each of these periods are presented by percentages; the nominator is the number of patients with a complication during the target period, the denominator is the number of patients alive at the beginning of the period. Differences in complication rates between patient subgroups were evaluated by Chi-squared tests. Kaplan-Meier complication curves were calculated for complications occurring during medical management. Log-rank tests were applied to evaluate subgroup differences. Univariable and multivariable logistic regression analyses were applied to describe the relationship between the timing of percutaneous coronary intervention and the risk of death or myocardial infarction, corrected for patient characteristics that influence prognosis ${ }^{[16]}$. The statistical significance of all tests was stated at the $P=0.05$ level.

\section{Results}

In PURSUIT, 9461 patients were treated with eptifibatide or placebo in addition to other antithrombotic and antiischaemic medication. Of these 9461 patients, 2430 underwent percutaneous coronary intervention within 30 days of enrolment. There were major differences in baseline characteristics between patients undergoing percutaneous coronary intervention within 30 days of enrolment and those not undergoing percutaneous coronary intervention. Of the patients who underwent percutaneous coronary intervention, 620 patients were treated within $24 \mathrm{~h}$ of randomization (day 1), 624 within $24-72 \mathrm{~h}$ (days 2-3), 614 within $73-168 \mathrm{~h}$ (days 4-7), and 561 within 169-720 h (days 8-30). The characteristics of the patient population according to the timing of percutaneous coronary intervention are described in Table 1. Patients undergoing percutaneous coronary intervention early after enrolment had a more favourable risk profile than those undergoing later percutaneous coronary intervention, as they were younger, less often had peripheral vessel disease, less often STsegment depression on admission, and had a lower mean systolic blood pressure.

\section{Complications during medical management}

During medical therapy, in the overall population including patients who subsequently underwent revascularization censored for intervention, the rate of death or infarction increased with time, with the steepest ascent occurring in the first 3 days (Fig. 1). Complication rates preceding percutaneous coronary intervention in patients undergoing percutaneous coronary intervention were higher than in the overall population, especially in patients who underwent intervention during days $0-3$ 


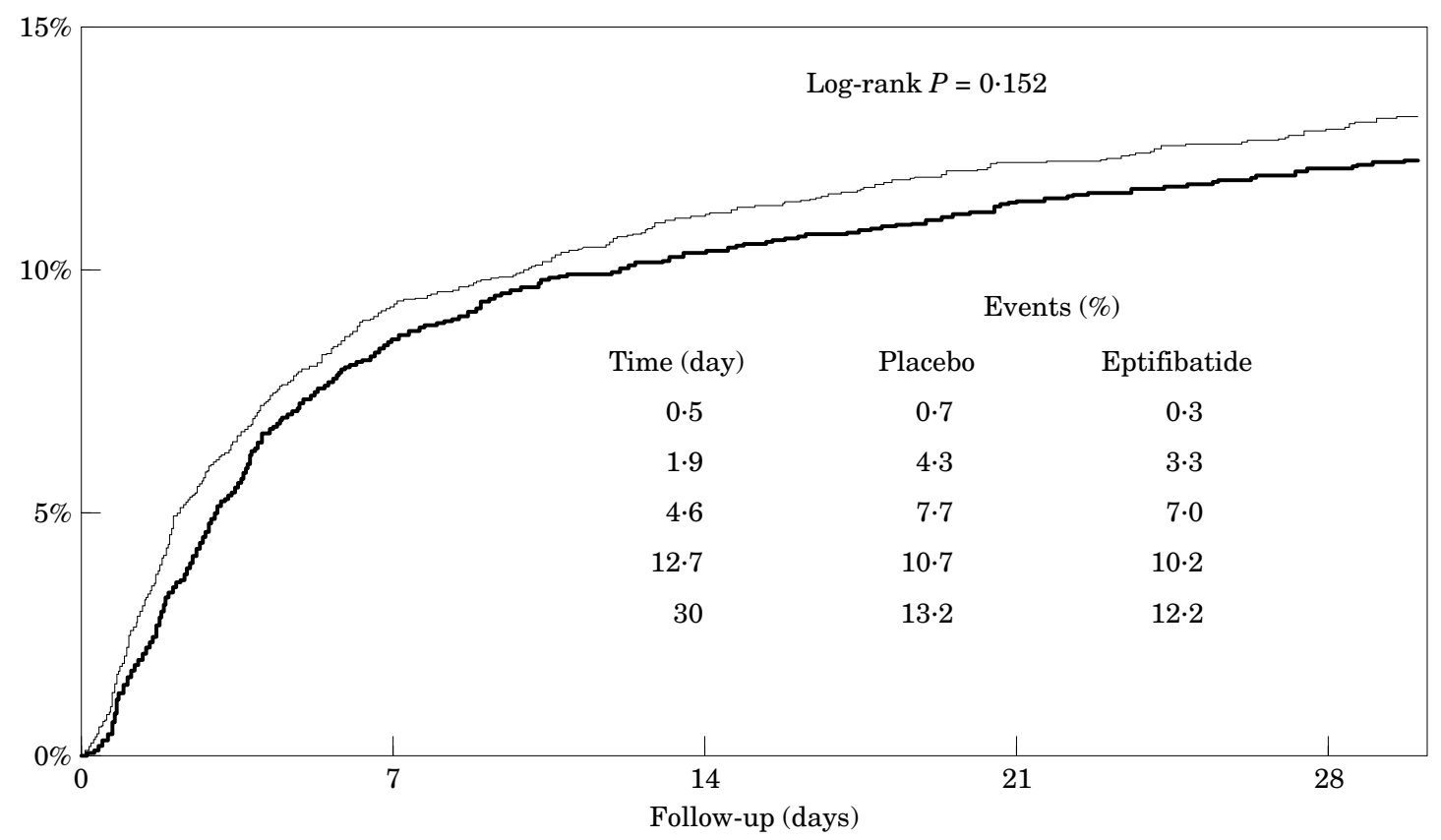

Figure 1 Kaplan-Meier curves showing the cumulative incidence of death or non-fatal myocardial infarction during the period of medical treatment alone, censored for percutaneous coronary intervention or bypass grafting if any, in patients randomly assigned to glycoprotein IIb/IIIa inhibition (bold line) or placebo for $72 \mathrm{~h}$.

and who were randomized to placebo. Complication rates on medical therapy on day 1 or until day 3 were only $0 \cdot 7 \%$ and $4 \cdot 3 \%$ (Fig. 1), while pre-procedural myocardial infarction occurred in $2 \cdot 2 \%$ and $8.7 \%$ of placebo patients undergoing percutaneous coronary intervention on day 1 and days $2-3$, respectively (Fig. 2). Treatment with eptifibatide was associated with a reduction in end-points: there were $13 \cdot 2 \%$ complications at 30 days in patients during medical treatment randomized to placebo, vs $12 \cdot 2 \%$ in eptifibatide (log-rank $P=0 \cdot 152$ ), excluding events associated with or occurring after percutaneous coronary intervention or CABG.

\section{Peri- and post-procedural complications}

A significant relationship was observed between the timing of percutaneous coronary intervention and the rate of peri-procedural death or myocardial infarction (Fig. 2), with the highest complication rate in the day 1 percutaneous coronary intervention cohort and the lowest complication rate in the days 8-30 cohort. The risk of peri-procedural complications in patients randomized to eptifibatide who underwent percutaneous coronary intervention on day 1 was significantly lower than that in patients randomized to placebo $(7 \cdot 2 \%$ vs $12 \cdot 1 \%$; $P=0.001)$. There were no significant differences in periprocedural complication rates between eptifibatide and placebo in the other percutaneous coronary intervention subgroups (remember that the PURSUIT study medication was administered during the first $72 \mathrm{~h}$ of enrolment only; see Method section). Rates of death or myocardial infarction occurring more than $48 \mathrm{~h}$ after the percutaneous coronary intervention procedure were low, and neither were related to the timing of percutaneous coronary intervention, nor the initial assignment to eptifibatide or placebo.

\section{Timing of percutaneous coronary intervention, eptifibatide treatment and overall complications during the 30-day follow-up}

Among all percutaneous coronary intervention patients, those undergoing percutaneous coronary intervention on day 1 who were randomized to eptifibatide had the lowest 30-day death or myocardial infarction rates $(9 \cdot 2 \%$; Fig. 2). This was significantly lower than patients undergoing percutaneous coronary intervention on day 1 who were randomized to placebo $(15.9 \% ; P=0.011)$. Eptifibatide therapy also reduced the 30-day complication rate in patients undergoing percutaneous coronary intervention on days 2-3 compared with placebo, although the difference in event rates $(14.0 \%$ vs $17 \cdot 7 \%)$ did not reach statistical significance. The 30 -day complication rate in all patients undergoing percutaneous coronary intervention during days $4-30$ was $16 \cdot 3 \%$. This was significantly higher than the complication rate in patients undergoing early percutaneous coronary intervention under the protection of eptifibatide $(9 \cdot 2 \%$ in the day 1 cohort; $P=0.002$, and $13.1 \%$ in the combined day 1 and days $2-3$ cohorts, $P=0 \cdot 007)$. There was, however, 

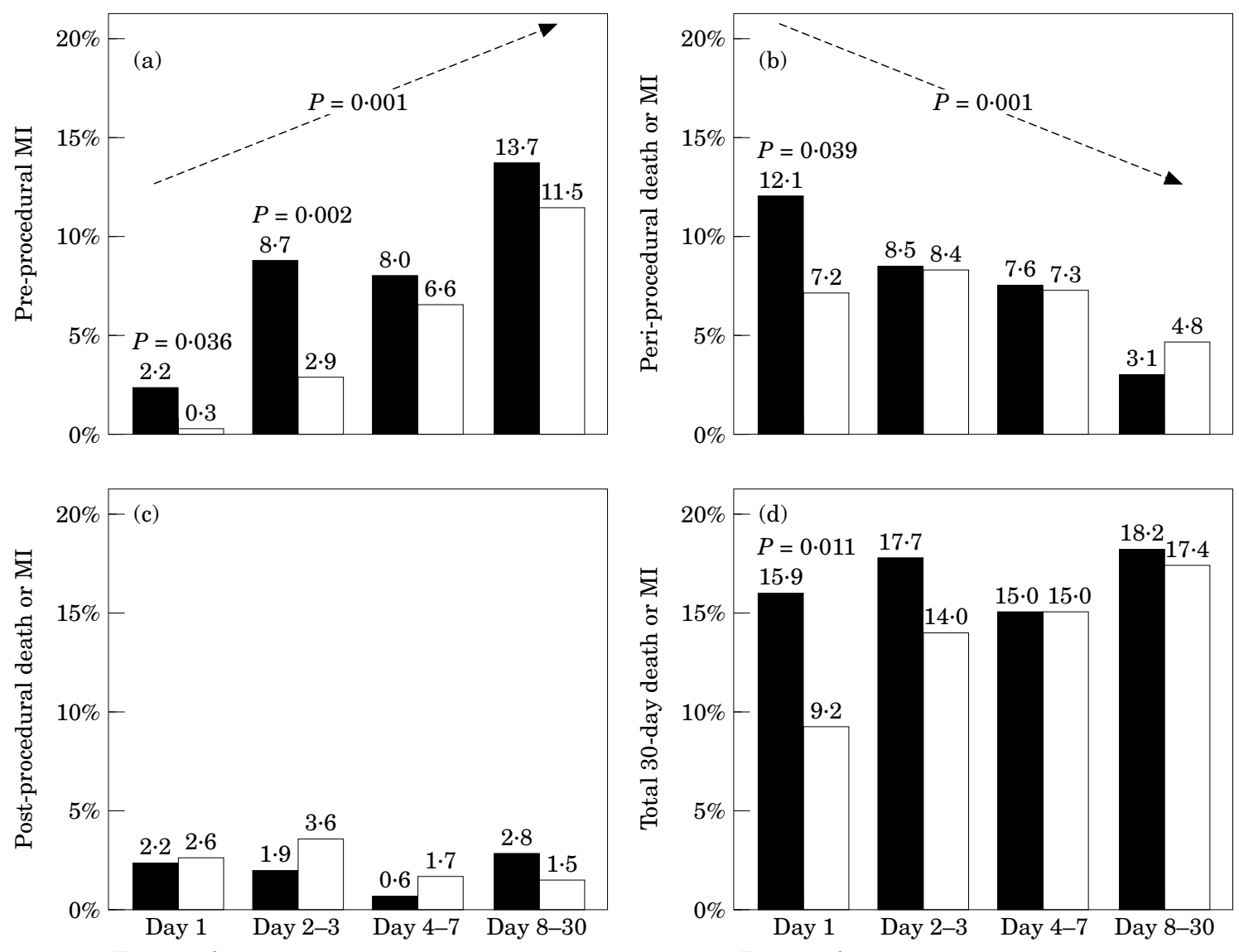

Timing of percutaneous coronary intervention

Timing of percutaneous coronary intervention

Figure 2 Percentage occurrence of cardiac complications in patients undergoing a percutaneous coronary intervention during days 0-30, randomly assigned to glycoprotein IIb/IIIa inhibition (white bars) or placebo for $72 \mathrm{~h}$. Cardiac complications were separated as occurring before the intervention, within $48 \mathrm{~h}$ of the start of the procedure (peri-procedural complications), or in the period $48 \mathrm{~h}$ after the procedure to 30 days of follow-up (post-procedural complications). A patient could have had an event in all three of these periods, but in each period only one event is counted per patient. The overall 30-day complication rates could therefore be lower than the sum of the complication rates in the separate periods.

no evidence of a differential benefit of eptifibatide therapy over placebo between the day 1 and days 2-3 percutaneous coronary intervention cohorts (BreslowDay test of homogeneity of odds ratios: $P=0 \cdot 297$ ).

The 30-day death or myocardial infarction rate in patients continuing with medical management was higher $(12 \cdot 2 \%-13 \cdot 2 \%$, Fig. 1$)$ than in patients undergoing percutaneous coronary intervention at day 1 under the protection of eptifibatide. Results of logistic regression analyses, however, indicate that this difference can largely be explained by the favourable risk profile of those undergoing early percutaneous coronary intervention. After correction for all determinants of risk, as mentioned in Table 1, percutaneous coronary intervention on day 1 under the protection of eptifibatide was associated with a similar outcome as 30-day medical management (corrected odds ratio and 95\% CI: $1 \cdot 0$ $[0 \cdot 7-1 \cdot 5])$. The corrected odds ratios for percutaneous coronary intervention on day 1 plus eptifibatide treatment versus any other percutaneous coronary intervention subgroup were in the range $0 \cdot 5-0 \cdot 7$. Differences in baseline characteristics as shown in Table 1 may have affected outcome among the early percutaneous coronary intervention cohorts. However, after correction for baseline characteristics by logistic regression, similar results were obtained in an analysis using investigator-defined myocardial infarction as the end-point.

\section{Discussion}

The present analysis indicates that outcome is favourable in patients with acute coronary syndrome without persistent ST-segment elevation undergoing percutaneous coronary intervention when such a procedure is performed within $24 \mathrm{~h}$ of admission under protection of a platelet glycoprotein IIb/IIIa receptor blocker. Thirtyday rates of death or myocardial infarction were only $9.5 \%$ for those undergoing percutaneous coronary 
intervention within $24 \mathrm{~h}$, while treated with eptifibatide, compared with $14 \cdot 3 \%$ to $16.5 \%$ for later percutaneous coronary intervention, or $12 \cdot 2 \%$ to $13 \cdot 2 \%$ for no percutaneous coronary intervention.

\section{Benefit of early revascularization}

The recently reported FRISC-II study of an early invasive versus a non-invasive treatment strategy demonstrated a clear benefit of an early invasive strategy and revascularization when appropriate at 6 months and 12 months of follow-up ${ }^{[6]}$. Patients randomized to the early revascularization strategy in FRISC-II underwent coronary angiography and subsequent revascularization if an obstruction of $\geq 70 \%$ of the diameter was observed in a major coronary artery. It should be noted that early percutaneous coronary intervention was performed at a median of 4 days after admission, and surgery at 7 days. In FRISC-II non-invasive treatment advised coronary angiography and revascularization when appropriate in patients with refractory or recurrent symptoms. By 10 days, $71 \%$ of patients in the invasive group had undergone coronary revascularization, versus $9 \%$ in patients allocated to continuing medical therapy. Complication rates (death or myocardial infarction) at 42 days were $8 \cdot 6 \%$ and $11 \cdot 8 \%$, respectively $(P=0 \cdot 009)$. These findings were confirmed recently by the TACTICS study (reported at the American Heart Annual Sessions, November 2000 ${ }^{[7]}$. Earlier randomized investigations, such as TIMI-3b and VANQWISH, failed to demonstrate favourable results of an early invasive treatment strategy ${ }^{[4,5]}$. A sizeable proportion of patients in these trials, however, did not undergo early revascularization as assigned, while many patients allocated to a medical treatment strategy underwent an early intervention. It should also be noted that these studies were performed in the pre-stent era and without platelet glycoprotein IIb/IIIa receptor blockers. In TACTICS all patients received a platelet glycoprotein IIb/IIIa receptor blocker, tirofiban, and most patients undergoing percutaneous coronary intervention received stents. In PURSUIT stents were used in $50 \%$ of all percutaneous coronary intervention procedures.

The present retrospective analysis does not confirm or refute a benefit for systematic early revascularization. The apparent benefit of revascularization was explained in part by differences in patient characteristics, and was no longer apparent using multivariable analysis. Patients were not randomized to undergo either an early invasive or conservative treatment strategy, but were managed according to the discretion of the treating physicians. The reasons for performing, or not, a specific intervention in a given patient were not recorded in PURSUIT. The indication for intervention in clinical practice should be based on recent guidelines as published by the European Society of Cardiology ${ }^{[17]}$ and the American organizations ${ }^{[18]}$, taking into account individual risk assessment, particularly elevated cardiac troponin levels and recurrent ischaemia.

\section{Timing of intervention in patients scheduled for revascularization}

When a decision to perform a revascularization in a given patient is made, three factors which determine the optimal timing of revascularization should be taken into account: the risk of complications before the intervention, the procedure-related risk and the risk after completion of the procedure.

The present analysis confirms earlier observations of the incremental risk of death or myocardial infarction while receiving medical therapy. This risk is particularly high early after admission, and gradually diminishes over time. Treatment with platelet glycoprotein IIb/IIIa receptor blockers and other antithrombotic therapy moderately reduces the risk under medical therapy, as illustrated in Fig. $1^{[19-21]}$. In patients subsequently scheduled for percutaneous coronary intervention, in the present study, the risk of pre-procedural complications clearly increased with time both in patients receiving placebo as well as eptifibatide (Fig. 2(a)). This risk was lower in the latter group, particularly in the first 3 days when the drug was administered.

As in other studies procedure-related complications, particularly myocardial infarction, were most frequent in patients undergoing early percutaneous coronary intervention (Fig. 2(b)) $)^{[10,11]}$. This risk was significantly reduced by the platelet glycoprotein IIb/IIIa receptor blocker, particularly when procedures were performed on day 1 . These findings are in agreement with other studies with platelet glycoprotein IIb/IIIa receptor blockers in patients undergoing percutaneous coronary intervention, which revealed a reduction of about 30 $50 \%$ in peri-procedural thrombotic complications, both with balloon angioplasty and with stents ${ }^{[22-26]}$, including patients with acute coronary syndrome without persistent ST-segment elevation ${ }^{[22,25]}$.

In all patient groups, events after the revascularization procedure were infrequent, and independent of the timing of such a procedure (Fig. 2(c)). Again, this is in agreement with observations in many other studies of patients undergoing percutaneous coronary intervention, where most events occurred in association with the procedure $^{[22-26]}$.

In the present study, the reduction of peri-procedural events (within $48 \mathrm{~h}$ of a percutaneous coronary intervention) was greater than the reduction of spontaneous events, pre-intervention. Overall outcome was superior in patients undergoing very early intervention, within $24 \mathrm{~h}$ or at least within the first 3 days after enrolment, while receiving the platelet glycoprotein IIb/IIIa receptor blocker eptifibatide (Fig. 2(d) $)^{[6,22-26]}$.

\section{Limitations}

This study is retrospective, and selection bias may have contributed to the observations as reported. However, in PURSUIT, the timing of intervention was determined mostly by local facilities and customs. Very early 
interventions were performed predominantly in the U.S.A., and later interventions in Europe, independent of other patient characteristics (Table 1). In order to correct for differences in baseline characteristics of patients revascularized at different time intervals, a multivariable analysis was performed. In this analysis, the effect of timing of an intervention on outcome remained statistically significant (odds ratio $0 \cdot 0-0 \cdot 7, P=0 \cdot 002$ ).

However, though the benefit of intervention by a glycoprotein IIb/IIIa receptor blocker within $24 \mathrm{~h}$ would be less than reported in this study, there is no evidence that outcome would be worse with early intervention. Therefore it seems appropriate, once a decision has been made to perform a percutaneous intervention in a particular patient, to proceed as soon as feasible, and not opt for a prolonged period of stabilization.

It should also be appreciated that the precise timing of an event in relation the start of a procedure (pre- or peri-percutaneous coronary intervention) is complex, particularly when only limited data are available to the clinical events committee. Peri-procedural myocardial infarction was defined with a higher cut-off value for creatine kinase MB-fraction than myocardial infarction in other intervals. This was chosen to adhere to the original PURSUIT protocol. Analysis with other cut-off values for myocardial infarction (three and five times the upper limit of normal, also for post-procedural myocardial infarction) did not influence results.

Furthermore, the more sensitive definition of spontaneous, not procedure-related, myocardial infarction as applied by the clinical events committee (at least one creatine kinase MB-fraction value above the upper limit of normal) may have prompted this committee to declare myocardial infarction before the procedure, whereas during the procedure much higher enzyme elevations had occurred. This may explain the greater than expected benefit from pre-procedural events in patients undergoing percutaneous coronary intervention on days 2 and 3 and the smaller than expected benefit of eptifibatide in peri-procedural events on days 2 and 3. Thus the overall 30-day death and myocardial infarction rate will be more reliable than the rate recorded for pre- and post-procedure intervals. According to the opinion of the local investigators, the difference in pre-procedural myocardial infarction rates between placebo and eptifibatide in the days $2-3$ cohort was smaller $(6 \cdot 3 \%$ vs $2 \cdot 9 \% ; P=0.043)$, but the difference in peri-procedural complications larger $(7 \cdot 6 \%$ vs $3 \cdot 6 \%$; $P=0.029)$. Using investigators' assessments, the reduction of peri-procedural myocardial infarction by eptifibatide was similar on day 1 and days 2 to 3 . Furthermore, this analysis compared the improved outcome on 30 days for patients undergoing intervention at day 1 , while receiving eptifibatide $(P=0 \cdot 011)$.

\section{Conclusion}

The present analysis of data from the PURSUIT study suggest that patients with acute coronary syndromes without persistent ST-segment elevation undergoing percutaneous coronary intervention benefit most from early intervention by a glycoprotein IIb/IIIa receptor blocker. Deferral of percutaneous coronary intervention has no advantage once the decision has been made to perform angioplasty. If percutaneous coronary intervention is deferred for practical or logistic reasons and is performed in a more stable setting, it will be useful to continue intensive antiplatelet therapy or to restart such therapy at the time of the procedure (also beyond day 3 ).

These findings warrant confirmation by a prospective study, randomizing patients to very early or deferred intervention, while receiving intensive antithrombotic therapy before and during the intervention.

\section{References}

[1] Braunwald E, Jones RH, Mark DB et al. Diagnosing and managing unstable angina. Circulation 1994; 90: 613-22.

[2] Hillis WS. The continuing debate: conservative or interventional therapy for unstable coronary artery disease. Am J Cardiol 1997; 80: 51E-54E.

[3] Theroux P, Fuster V. Acute coronary syndromes. Unstable angina and non-Q myocardial infarction. Circulation 1998; 97: 1195-206.

[4] Theroux P, White H, David D et al. for the TIMI IIIB Investigators. Effects of tissue plasminogen activator and a comparison of early invasive and conservative strategies in unstable angina and non-Q-wave myocardial infarction: results of the TIMI IIIB trial. Circulation 1994; 89: 1545-56.

[5] Boden WE, O'Rourke RA, Crawford MH et al. Outcomes in patients with acute non-Q myocardial infarction randomly assigned to an invasive as compared with a conservative management strategy. N Engl J Med 1998; 338: 1785-92.

[6] The Fragmin and Fast Revascularization during Instability in Coronary artery disease (FRISC II) Investigators. Invasive compared with non-invasive treatment in unstable coronaryartery disease: Frisc II prospective randomised multicentre study. Lancet 1999; 354: 708-15.

[7] TACTICS TIMI-18 results were presented during the November 2000 annual sessions of the American Heart Association.

[8] Van Miltenburg-Van Zijl AJM, Simoons ML, Bossuyt PMM, Taylor TR, Veerhoek MJ. Variation in the use of coronary angiography in patients with unstable angina is related to differences in patient population and availability of angiography facilities, without affecting prognosis. Eur Heart $\mathbf{J}$ 1996; 17: 1828-35.

[9] Yusuf S, Flather M, Pogue J et al. Variations between countries in invasive cardiac procedures and outcomes in patients with suspected unstable angina or myocardial infarction without initial ST elevation. OASIS (Organisation to Assess Strategies for Ischaemic Syndromes) Registry Investigators. Lancet 1998; 352: 507-14.

[10] De Feyter PJ, Suryapranata H, Serruys PW et al. Coronary Angioplasty for Unstable Angina: Immediate and Late Results in 200 Consecutive Patients With Identification of Risk Factors for Unfavorable Early and Late Outcome. J Am Coll Cardiol 1988; 12: 324-33.

[11] Bentivoglio LG, Detre K, Yeh W, Williams DO, Kelsey SF, Faxon DP. Outcome of percutaneous transluminal coronary angioplasty in subsets of unstable angina pectoris. A report of the 1985-1986 National Heart, Lung, and Blood Institute Percutaneous Transluminal Coronary Angioplasty Registry. J Am Coll Cardiol 1994; 24: 1195-206.

[12] Boersma E, Akkerhuis M, Theroux P. Platelet glycoprotein IIb/IIIa receptor inhibition in Non-ST-Elevation acute 
coronary syndromes. Early benefit during medical treatment only, with additional protection during percutaneous coronary intervention. Circulation 1999; 100: 2045-8.

[13] Ronner E, Dykun Y, Van den Brand MJBM, Van der Wieken LR, Simoons ML. Platelet glycoprotein IIb/IIIa receptor antagonists. An asset for treatment of unstable coronary syndromes and coronary intervention. Eur Heart J 1998; 19: 1608-16.

[14] The PURSUIT trial investigators. Inhibition of platelet glycoprotein IIb/IIIa with eptifibatide in patients with acute coronary syndromes. N Engl J Med 1998; 339: 436-43.

[15] Harrington RA. Clinical trials in acute coronary syndromes: lessons from PURSUIT. Eur Heart J 1999; 1 (Suppl R): R28-R34.

[16] Boersma E, Pieper KS, Steyerberg EW et al. Predictors of outcome in patients with acute coronary syndromes without persistent ST-segment elevation. Results from an international trial of 9461 patients. Circulation 2000; 101: 2557-67.

[17] Bertrand ME, Simoons ML, Fox KAA et al. Management of acute coronary syndromes: acute coronary syndromes without persistent ST-segment elevation. Recommendations of the task force of the European Society of Cardiology. Eur Heart J 2000; 17: 1406-32.

[18] Braunwald E, Antman EM, Beasley JW et al. ACC/AHA guidelines for the management of patients with unstable angina and non-ST-segment elevation myocardial infarction: executive summary and recommendations. A report of the ACC/AHA task force on practice guidelines. Circulation 2000; 102: 1193-2009.

[19] Cohen M, Demers C, Gurfinkel EP et al., for the Efficacy and Safety of Subcutaneous Enoxaparin in Non-Q-Wave
Coronary Events Study Group. A comparison of lowmolecular weight heparin with unfractionated heparin for unstable coronary disease. N Engl J Med 1997; 337: 447-52.

[20] The FRISC Study Group (Fragmin during instability in coronary artery disease study group). Low-molecular-weight heparin during instability in coronary artery disease. Lancet 1996; 347: 561-8.

[21] Antman EM, McCabe CH, Gurfinkel EP et al. Enoxaparin prevents death and cardiac ischemic events in unstable angina/ non-Q wave myocardial infarction. Circulation 1999; 100: 1593-601.

[22] The EPIC Investigators. Use of a monoclonal antibody directed against the platelet glycoprotein IIb/IIIa receptor in high-risk coronary angioplasty. N Engl J Med 1994; 330: 956-61.

[23] The EPILOG Investigators. Platelet glycoprotein IIb/IIIa receptor blockade and low-dose heparin during percutaneous coronary revascularization. N Engl J Med 1997; 336: 1689-96.

[24] The EPISTENT investigators. Randomised placebocontrolled and balloon-angioplasty-controlled rial to assess safety of coronary stenting with use of platelet glycoproteinIIb/IIIa blockade. Lancet 1998; 352: 87-92.

[25] The CAPTURE Investigators. Randomised placebocontrolled trial of abciximab before and during coronary intervention in refractory unstable angina: the CAPTURE Study. Lancet 1997; 349: 1429-35.

[26] The ESPRIT investigators. Novel dosing regimen of eptifibatide in planned coronary stent implantation (ESPRIT): a randomised placebo-controlled trial. Lancet 2000; 356: 2037-44. 